\title{
Re-modeling and Simulation of an Economic Map System Based on System Dynamic Principles - Case Study in Southern Romania*
}

\author{
Mihail DUMITRACHE ${ }^{1,2}$, Valentina Constanța TUDOR ${ }^{3}$, Alina MĂRCUȚA ${ }^{3 *}$, Victor TIȚA ${ }^{3}$, Alexandru \\ SIPICĂ ${ }^{1}$, Doru Anastasiu POPESCU ${ }^{4}$, Nicolae BOLD ${ }^{4}$, Marius Mihai MIC $\mathbf{U}^{3}$ \\ ${ }^{1}$ National Institute for Research and Development in Informatics - ICI Bucharest, \\ 8-10 Mareșal Averescu Avenue, Bucharest, 01145, Romania \\ mihail.dumitrache@ici.ro, alexandru.sipica@ici.ro \\ ${ }^{2}$ University of Bucharest - Faculty of Letters, 5-7 Edgar Quinet Street, Bucharest, 010017, Romania \\ ${ }^{3}$ University of Agricultural Sciences and Veterinary Medicine Bucharest, 59 Maraști Bd, \\ Bucharest, 011464, Romania \\ valentina tudor@yahoo.com, alinamarcuta@yahoo.com (*Correspondingauthor), \\ victortita@yahoo.com,micumariusmihai@yahoo.com \\ ${ }^{4}$ University of Pitești, 1 Târgul din Vale, 110040, Pitești, Argeș County, Romania \\ dopopan@gmail.com, bold_nicolae@yahoo.com
}

\begin{abstract}
An economic environment has a series of variables that make it complex and hard to analyse. Many different aspects of this issue have been studied and taken into consideration in various papers from the specialised literature. Approaches related to the representation of an economic environment have been made based on historical data regarding enterprises in a geographic basin using graph theory principles. This paper presents a new approach to creating a model of an economic market on a geographic background area using System Dynamics principles based on this previous model. The model has particularities related to the area taken into study within the Romanian economic context and some aspects regarding the connections that are made between the enterprises within the geographic areas. This model presented in this paper represents a new implementation of the background model.
\end{abstract}

Keywords: Graph theory, Economic map, Enterprise, Model, Simulation.

\section{Introduction}

According to (Banciu D. et al., 2020) the Romanian digital transformation is in accordance with the European directives in this field, but also with the global trends of the 21 st century. Creating an image of an economic environment of a geographic market is a difficult task given the great number of parameters that must be taken into consideration. Due to this aspect, the exact representation of a system is a tedious work. A representation of the economic status of a geographical market was made in (Wang et al., 2018). In this paper, a modality of modeling one of these systems is presented based on a case study in a village in southern Romania, with a pronounced agricultural character (Stoian et al., 2011) related to the high number of agricultural enterprises (Necula, 2011). Previous approaches were related to the creation of the model based on graph structures and behavior (Bold, 2016; Tița \& Bold, 2016; Tița et al., 2018). This paper extends the model by transferring the structure to a model based on System Dynamics (SD) principles (Saavedra et al., 2018) and simulating it based on the cash flows that circulate throughout the system (Coyle, 1977).

The novelty of the approach, in comparison with some other studies based on the same principles (Koulouriotis et al., 2001, Yiwen et al., 2000 etc.), is materialized in the usage of various indexes.

In short, the model built in the previous papers (Bold, 2016; Tița \& Bold, 2016; Tița et al., 2018) will be presented in Section 2 and the new approach based on System Dynamic principles in the next sections. Section 3 presents the model built using System Dynamic principles, with a graphical representation of the model and a short simulation. Conclusions shows several aspects regarding the results and suggestions for future work.

\section{Presentation of Base Model and Environment}

Even if the idea of modelling an economic market of enterprises is not novel (Doll et al., 2006; Grabher, 2006), the approach presented in this paper includes

\footnotetext{
* This paper is the extension of the study continued in the paper of Tița, V. \& Bold, N. (2016). Educational Aspects of Market Mapping: Student Learning of Economic Issues Regarding Markets Using a Model Based on Graphs. In Proceedings of the 11th International Conference On Virtual Learning, Bucharest University Press (ISSN 1844-8933), (pp. 329-333). The novel elements of this paper are the construction of the model using different principles and concepts than graph theory, namely the System Dynamic principles. This approach is refined from the simulation point of view and the results are enriched by using this approach.
} 
several aspects that can be taken into consideration as important parts of the determination of the relationships between the enterprises in the geographic area (Nagurney, 2006).

The building blocks of the model include the mathematical foundations of the graph theory and some methods used in the field to determine various graph proprieties (Roberts, 1989). In this matter, the market is modelled as a directed graph, with the vertices representing the enterprises and the edges the economic relationships which are or can be established between the vertices (Quoniam et al., 2007).

In order to establish the methodology of the model, the theoretical background of the approach has been tested on a case scenario which would contain a large part of the cases that can be met in practice (Duque et al., 2009; Archibugi et al., 1999). Thus, the model has been refined as a geographic map of Serbanesti village, situated in Olt County, in the southern part of Romania.

The methodology of the model consists in the next steps:

1. the enterprises are analysed and the necessary parameters for these enterprises are found;

2. the affinities between the pairs of enterprises are found;

3. the potential relationships between the enterprises are established;

4. some characteristics of the market are found, analysed and studied using graph proprieties;

5. finally, suggestions related to economic development are formulated.

The list of all the Limited Liability Companies (LLC) from the village are presented in Table 1.

Table 1. The list of enterprises in Șerbănești and their characteristics

(Source: determinations based on data from topfirme.com)

\begin{tabular}{|c|c|c|c|}
\hline Id & Enterprise & Total costs of the enterprise (thousand lei) & Turnover (thousand lei) \\
\hline 1 & Longin & 25390.05 & 27290.05 \\
\hline 2 & Neaga Impex & 3472.00 & 3772.55 \\
\hline 3 & Agrospeed Production & 2901.30 & 2535.66 \\
\hline 4 & Cafe Bar Central & 71.95 & 75.76 \\
\hline 5 & Hekatos Servcons & 169.20 & 202.49 \\
\hline 6 & $\begin{array}{c}\text { Cabinet Medical dr. Stolojan } \\
\text { Verginia }\end{array}$ & 79.38 & 114.57 \\
\hline 7 & Codrut Cons & 422.02 & 442.49 \\
\hline 8 & Rositrans & 67.41 & 119.15 \\
\hline 9 & Adrienet Ser Alexia & 0.00 & 19.76 \\
\hline 10 & 3 Ciobănei & 94.35 & 115.37 \\
\hline 11 & Rai Club 2006 & 18.09 & 13.22 \\
\hline 12 & Forest Serb & 585.53 & 619.22 \\
\hline 13 & Tehno Asstadi & 114.07 & 116.00 \\
\hline 14 & Villa Rubia Lucicor & 82.54 & 71.53 \\
\hline 15 & Mihviando & 31.71 & 20.09 \\
\hline 16 & Alinda Garny & 10.58 & 30.21 \\
\hline 17 & Denisa Impex & 0.00 & 0.00 \\
\hline 18 & Cristi \& Vali & 10.72 & 14.09 \\
\hline 19 & Iul Marieli & 0.00 & 0.00 \\
\hline 20 & Sos Tomescu MG & 28.54 & 22.40 \\
\hline 21 & Com Dinculescu & 2.025 & 2.07 \\
\hline 22 & Olteanu Marin Bodgan Prestserv & 0.00 & 0.00 \\
\hline 23 & Cezar \& Daniel Construct & 0.00 & 0.00 \\
\hline 24 & Cromat & 24.96 & 19.63 \\
\hline 25 & Dorflo GRS Construct & 0.00 & 0.00 \\
\hline 26 & Luiza Alidan SRL & 345.09 & 357.01 \\
\hline 27 & Max-Ștefan Construct & 0.00 & 0.00 \\
\hline 28 & Armonia & 18883.10 & 32.10 \\
\hline 29 & Individuals & - & - \\
\hline
\end{tabular}


As it can be seen in Table 1, the economic environment in the village comprises a variety of economic activities. Obviously, the agricultural aspect accounts for the majority of the economic market, but other branches are represented in the area, mainly those related to commerce and to activities related to this sector. The actual configuration, inclined to an agricultural characteristic, already leads to the creation of suggestions related to economic development, which are connected to the agricultural domain.

Figures 1 and 2 present the statistical aspects of the economic environment within Șerbănești. While Figure 1 presents the number of enterprises and employees within the village, Figure 2 presents their distribution on economic sectors.

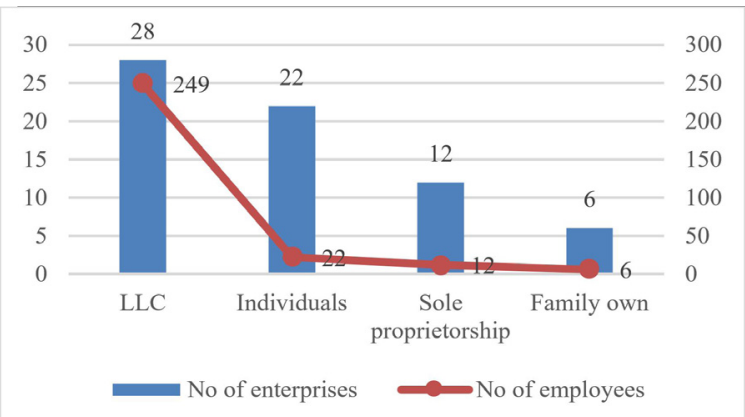

Figure 1. Number of enterprises and employees within Șerbănești (Source: topfirme.com)

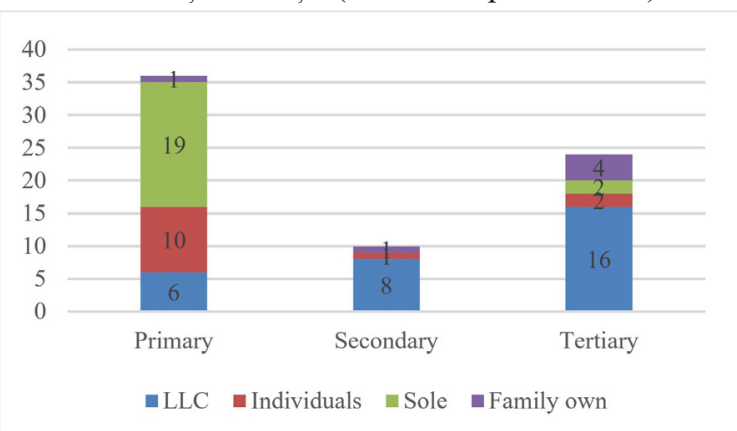

Figure 2. Number of enterprises and employees within Șerbănești, classified according to economic sectors (Source: topfirme.com)
It can be observed that a large number of people work within limited liability companies (LLC) and the largest number of enterprises are established in this legal form. Also, other legal forms are represented in the economic environment, their number being close to those of LLC, but with a smaller representation of the number of employees. The rest of the population works within non-organized forms of activity, in subsistence households or involved in outer economic enterprises.

It can also be noticed that the distribution of the enterprises per sectors is typical for a rural area distribution. The majority of the enterprises are related to agriculture, followed by the tertiary sector, represented by commercial activities. The industrial activity has the lowest number of enterprises, which is quite normal for a rural economic environment.

The relations have been established based on the representation of the geographic market in the form of a mathematical model based on graph structures. The input data consists in 15 characteristics of the enterprises based on which an Affinity Index is calculated.

The output results consist in a graph representation of the economic environment, presented in Figure 3 (a), and the bi-dimensional arrays that store the relationship data between the enterprises. Using this codification, other useful data could be extracted, such as the agri-food chains (Geunes \& Pardalos, 2005 ) that can be established within the village, as shown in Figure 3 (b) by applying traditional literature graph algorithms (Roy-Warshall).

The Affinity Index was calculated using the formula presented in Equation (1), with the coefficients established according to their importance within the economic context. In

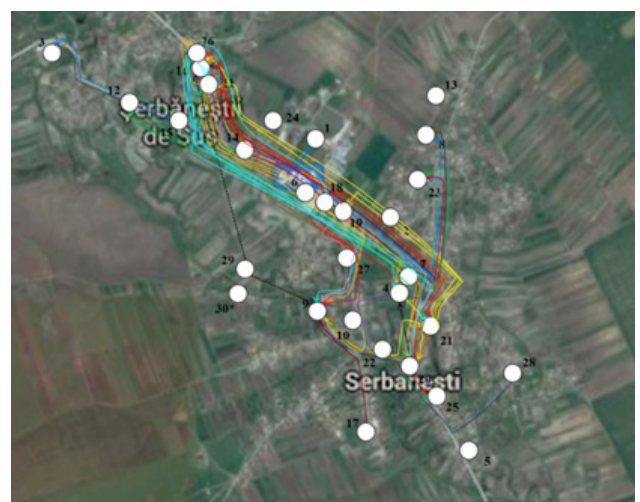

(a)

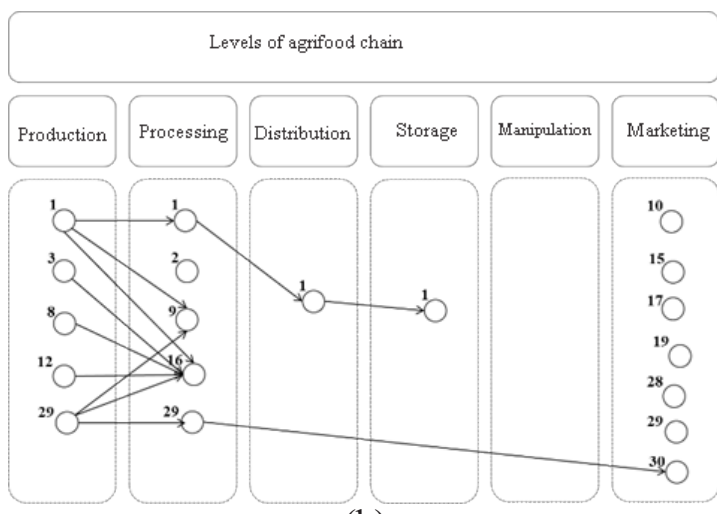

(b)

Figure 3. (a) Economic map as a graph; (b) Secondary results of the model, showing agri-food chains 
the calculus of the index, aspects related to the nature of the economic activity, the geographic and physical approach, the human relation and economic profitability and power have been considered and used. The coefficients of each type of affinity are still a subject that can be addressed in a further study in order to make a model that would approach to the reality. Within Equation (1), $\mathrm{E}_{1}$ and $\mathrm{E}_{2}$ are two enterprises, where $\mathrm{E}_{1}$ is considered the provider enterprise and $\mathrm{E}_{2}$ the client enterprise, and $\operatorname{Af}\left(\mathrm{E}_{1}, \mathrm{E}_{2}\right)$ is the Affinity Index between the two enterprises.

Af $\left(E_{1}, E_{2}\right)$

$=\frac{A, 50 \times A f_{C C}+0,30 \times A f_{P}+0,15 \times A f_{g e o}+0,05 \times A f_{U}+0,05 \times A f_{\text {inc }}}{0,5+0,3+0,15+0,05+0,05}$

Within the equation, the next notations have been taken into consideration:

- Af is the affinity index, $\left(0 \leq \operatorname{Af}\left(\mathrm{E}_{1}, \mathrm{E}_{2}\right) \leq 1\right)$

- $A f_{c}$ is considered the affinity based on keywords; for a stronger connection, some input (I) and output (O) keywords have been defined for each enterprise; the I keywords define the raw material needed for the production and the $\mathrm{O}$ keywords define the products / services resulted from the activity of the enterprise; the value of the index is the percentage of the matched $\mathrm{E}_{1} \mathrm{O}$ keywords and $\mathrm{E}_{2} \mathrm{I}$ keywords;

- $A f$ is the affinity based on practical study, made on the field;

- $A f_{\text {geo }}$ is the affinity based on geographic proximity; the index is calculated based on the classical spatial formula between two points described in the literature;

- $A f_{U}$ is the affinity based on human relationships between the managers; this has been empirically established, thus, is prior to further study;

- $A f_{\text {inc }}$ is the affinity based on trust, calculated as an average of the profit rate for the last three years.

$\mathrm{E}_{1}$ is considered to be the provider and $\mathrm{E}_{2}$ the customer enterprise.

Regarding these relations, their existence is, obviously, based on the real economic interaction between two entities. Their nature is dual:

- on one hand, the relation can be studied for its existence (this type of relation will be denoted by RE) - if two entities can be related. This characteristic can be solved by studying compatibility between the entities based on the membership to a Nomenclature of Economic Activities (NACE) code (Clasificarea Activitătilor din Economia Națională - CAEN in Romanian); on the other hand, the relation can have a certain intensity (denoted by RI) - to what extent the two entities capable of being related are actually capable of being related. In other words, the intensity refers to the economic power of the provider to sustain the client and vice versa.

A relationship between the enterprises is considered valid if Af value is higher than 0.5. Also, due to economic power, a relationship for a provider enterprise $\left(\mathrm{E}_{\mathrm{p}}\right)$ is considered valid if the sum of the costs of all clients enterprise $\left(\mathrm{E}_{\mathrm{C} 1}, \mathrm{E}_{\mathrm{C} 2}\right.$, $\left.\ldots, \mathrm{E}_{\mathrm{Ck}}\right)$ is equal to the costs of the provider, as shown in Figure 4 and by equations (2) and (3).

$$
\begin{aligned}
& C o_{E_{P}}=\sum_{i=1}^{k} C o_{E C_{i}}, k>1 \\
& C o_{E_{P}}=\sum_{i=1}^{k} C o_{E C}, k=1
\end{aligned}
$$

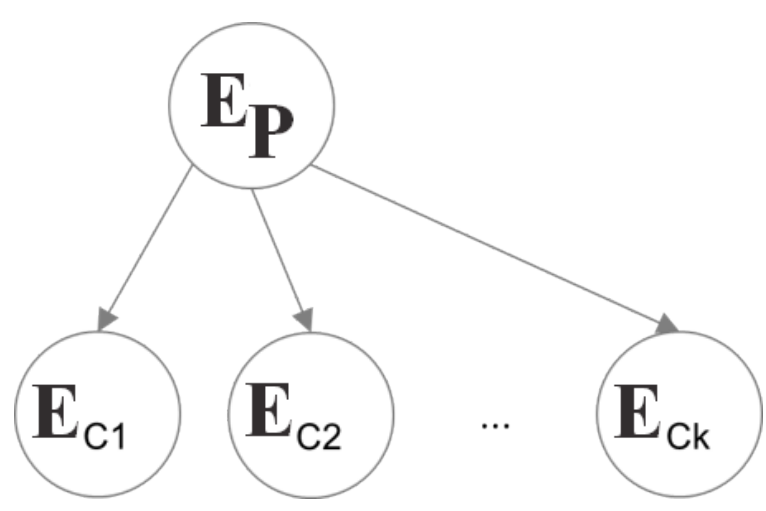

Figure 4. Mapping relations based on economic power

Equations (2) and (3) describe the particular and practical nature of the relation between two enterprises. Its purpose is to determine the economic capacity of an enterprise to be provider for a $k$ number of potential client enterprises. Thus, there has been considered that the costs of the provider $\left(\mathrm{Co}_{\mathrm{EP}}\right)$ must comprise the costs of all its clients $\left(\mathrm{Co}_{\mathrm{EC} 1}, \mathrm{Co}_{\mathrm{EC} 2}, \ldots, \mathrm{Co}_{\mathrm{ECk}}\right)$ in order for the economic relation to be viable. This nature of the relation is graphically shown in Figure 4. In this notation, costs refer to the general costs of an enterprise based on the financial documents.

An implementation of the whole theoretical concept has been made in order to find the affinities and the relations between the enterprises within the chosen geographic area, denoted by integer numbers from 1 to the total number of the enterprise (in the first column, No. ord.). The obtained results are shown in the third column (column no. 2) of the Table 2 . The last 
two columns of the Table 2 show the enterprises that can sustain economically the clients (column 3 ) or the providers (column 4) in both ways of the relation from the set of enterprises found in column 2. While the relations have been generated based on the pairs of affinity index, the agri-food chains have also been studied, in order to obtain a broader view of the relationships between the enterprises from an agricultural and food industry point of view. As for the case study, the most important finding is the need for the establishment of enterprises that might serve as chain parts for the whole local community economic environment.

\section{The SD-based Model, Results and Comparison with previous Models}

System Dynamics is a computer-aided approach used for policy analysis and design. It applies to dynamic problems arising in complex social, managerial, economic, or ecological systemsliterally any dynamic system characterized by

Table 2. Connections based on the logic shown in Figure 4

\begin{tabular}{|c|c|c|c|c|}
\hline \multirow[b]{2}{*}{ No. ord. } & \multirow[b]{2}{*}{ Enterprise } & \multirow{2}{*}{$\begin{array}{c}\text { Potential client } \\
\text { enterprises by RE } \\
\text { (relation of existence) }\end{array}$} & \multicolumn{2}{|c|}{$\begin{array}{l}\text { Potential client enterprises by RI } \\
\text { (intensity of relation) }\end{array}$} \\
\hline & & & $\begin{array}{c}\text { Provider enterprises } \\
\text { when client turnover } \\
\text { not exceeded }\end{array}$ & $\begin{array}{c}\text { Client enterprises } \\
\text { when provider } \\
\text { turnover not exceeded }\end{array}$ \\
\hline 0 & 1 & 2 & 3 & 4 \\
\hline 1 & Longin & $3,8,9,16$ & 89163 & 38916 \\
\hline 2 & Neaga Impex & 24 & 24 & 24 \\
\hline 3 & Agrospeed Production & 16 & 16 & 16 \\
\hline 4 & Cafe Bar Central & $9,11,18,20,21,26$ & 111892021 & 1811 \\
\hline 5 & Hekatos Servcons & - & & \\
\hline 6 & $\begin{array}{c}\text { Cabinet Medical dr. Stolojan } \\
\text { Verginia }\end{array}$ & - & & \\
\hline 7 & Codrut Cons & $14,23,25,27$ & 14 & 23 \\
\hline 8 & Rositrans & 16 & 16 & 16 \\
\hline 9 & Adrienet Ser Alexia & - & & \\
\hline 10 & 3 Ciobănei & 9 & 9 & 9 \\
\hline 11 & Rai Club 2006 & $4,9,18,20,21,26$ & 2021 & 42618 \\
\hline 12 & Forest Serb & $14,16,23,25,27$ & 1416 & 2325 \\
\hline 13 & Tehno Asstadi & - & & \\
\hline 14 & Villa Rubia Lucicor & - & & \\
\hline 15 & Mihviando & 9 & 9 & 9 \\
\hline 16 & Alinda Garny & - & & \\
\hline 17 & Denisa Impex & 9 & & \\
\hline 18 & Cristi \& Vali & $4,9,11,20,21,26$ & 91121 & 1120 \\
\hline 19 & Iul Marieli & 9 & & \\
\hline 20 & Sos Tomescu MG & $4,9,11,18,21,26$ & 114262118 & 212618 \\
\hline 21 & Com Dinculescu & $4,9,11,18,20,26$ & 11 & 918 \\
\hline 22 & $\begin{array}{l}\text { Olteanu Marin Bodgan } \\
\text { Prestserv }\end{array}$ & $1,3,8,29$ & & \\
\hline 23 & Cezar \& Daniel Construct & - & & \\
\hline 24 & Cromat & - & & \\
\hline 25 & Dorflo GRS Construct & - & & \\
\hline 26 & Luiza Alidan SRL & $4,9,11,18,20,21$ & 1841192021 & 114 \\
\hline 27 & Max-Ștefan Construct & - & & \\
\hline 28 & Armonia & 9 & 9 & 9 \\
\hline 29 & Sole traders & 9,16 & 169 & 916 \\
\hline 30 & External enterprises & $\begin{array}{l}1,3,4,6,7,8,10,11,12, \\
14,15,17,18,19,20,21 \\
22,23,25,26,27,28,29\end{array}$ & $\begin{array}{l}1312726810428 \\
14201196151821\end{array}$ & 257 \\
\hline
\end{tabular}


interdependence, mutual interaction, information feedback, and circular causality.

As (Zhikun et al., 2018) present that complexity science has attracted substantial attention from scholars in various disciplines, ranging from physics, economics, and computer science to social science. The model present in this paper has been improved in order to be as close as possible to reality, namely to provide a better visualisation of the relations established between the enterprises and a clearer simulation of the enterprises' behaviour. Thus, the simulation has been carried out for the model based on a System Dynamic approach by plotting the costs of the enterprises for 5 years. Enterprises have been considered stock variables, relations have been established as flows and some rates due to time constraints (inflation) have been also been taken into consideration.
Stocks (levels, in this case, the costs of the enterprises) and the flows (rates, in this case, the relations between the enterprises) that affect them are essential components of the structure of the system. Stocks (accumulations, state variables) are the memory of a dynamic system and also the sources of its unbalanced and dynamic behaviour.

The concept of System Dynamics (SD) is defined by (Forrester, 1994) as a top-down information feedback method. The essence of this method (Nasirzadeh et al, 2018) is the feedback structures with high order, multiloop, and nonlinearity. SD is a well-developed approach for visualizing, analyzing, and understanding the complex dynamic feedbacks.

The model construction is presented in Figure 5. After the simulation of this model, some results have been obtained for a 5-years plot, as shown in Table 3.

Table 3. Plot for 5 years of the costs of the enterprise (Source: determination using AnyLogic)

\begin{tabular}{|c|c|c|c|c|c|c|}
\hline \multirow[b]{2}{*}{ Enterprise } & \multicolumn{6}{|c|}{ Provisioned costs resulted after the simulation } \\
\hline & Year 0 & Year 1 & Year 2 & Year 3 & Year 4 & Year 5 \\
\hline plot: E01_Lon & 27290.05 & 27718.95 & 28794.82 & 29619.94 & 31276.33 & 32432.23 \\
\hline plot: E02_Nea & 3772.55 & 3192.108 & 2625.751 & 1961.409 & 1429.041 & 679.314 \\
\hline plot: E03_Agr & 2535.66 & 2041.323 & 1557.972 & 992.1584 & 537.319 & -100.691 \\
\hline plot: E04_Caf & 75.76 & 64.7062 & 53.9544 & 41.07867 & 31.09815 & 16.61863 \\
\hline plot: E05_Hek & 202.49 & 174.4813 & 147.1825 & 115.1267 & 89.48087 & 53.28901 \\
\hline plot: E06_Cab & 114.57 & 101.7343 & 89.2568 & 74.56512 & 62.86017 & 46.25651 \\
\hline plot: E07_Cod & 442.49 & 372.6742 & 304.5628 & 224.4379 & 160.5251 & 70.16329 \\
\hline plot: E08_Ros & 119.15 & 108.5901 & 98.36213 & 86.27367 & 76.69866 & 63.0183 \\
\hline plot: E09_Adr & 19.76 & 17.26925 & 14.76719 & 12.53513 & 9.846199 & 7.175265 \\
\hline plot: E10_Cio & 115.37 & 100.1087 & 85.24892 & 67.72593 & 53.8007 & 34.0266 \\
\hline plot: E11_Rai & 13.22 & 9.585477 & 6.009452 & 1.963066 & -1.46847 & -6.05432 \\
\hline plot: E12_For & 619.22 & 522.2968 & 427.7433 & 316.5391 & 227.801 & 102.3779 \\
\hline plot: E13_Teh & 116.00 & 96.79801 & 78.0485 & 56.07335 & 38.44115 & 13.64781 \\
\hline plot: E14_Vil & 71.53 & 56.93374 & 42.6424 & 26.05168 & 12.53716 & -6.19583 \\
\hline plot: E15_Mih & 20.09 & 14.81728 & 9.658137 & 3.568417 & -1.26163 & -8.10993 \\
\hline plot: E16_Ali & 30.21 & 27.71419 & 25.2719 & 22.63968 & 20.23128 & 17.1959 \\
\hline plot: E17_Den & 0.00 & -2.73906 & -5.52468 & -8.35894 & -11.2315 & -14.1758 \\
\hline plot: E18_Cri & 0.00 & -2.73906 & -5.52468 & -8.35894 & -11.2315 & -14.1758 \\
\hline plot: E19_Iul & 0.00 & 0.25439 & 0.512104 & 0.746891 & 1.021332 & 1.298628 \\
\hline plot: E20_Sos & 22.40 & 17.49264 & 12.69002 & 7.074389 & 2.552287 & -3.77808 \\
\hline plot: E21_Com & 2.07 & 1.220508 & 0.372416 & -0.48708 & -1.34879 & -2.34331 \\
\hline plot: E22_Olt & 0.00 & 0.25439 & 0.512104 & 0.746891 & 1.021332 & 1.298628 \\
\hline plot: E23_Cez & 0.00 & -0.50878 & -1.02421 & -1.49378 & -2.04266 & -2.59726 \\
\hline plot: E24_Cro & 19.63 & 15.08444 & 10.62721 & 5.481907 & 1.253274 & -4.55955 \\
\hline plot: E25_Dor & 0.00 & -0.50878 & -1.02421 & -1.49378 & -2.04266 & -2.59726 \\
\hline plot: E26_Lui & 357.01 & 300.5402 & 245.467 & 180.5034 & 128.9098 & 55.68427 \\
\hline plot: E27_Max & 0.00 & -0.50878 & -1.02421 & -1.49378 & -2.04266 & -2.59726 \\
\hline plot: E28_Arm & 32.10 & -3444.7 & -6871.09 & -10848.8 & -14087.4 & -18559.4 \\
\hline plot: E29_PFA & 0.00 & -0.25439 & -0.5121 & -0.74689 & -1.02133 & -1.29863 \\
\hline
\end{tabular}




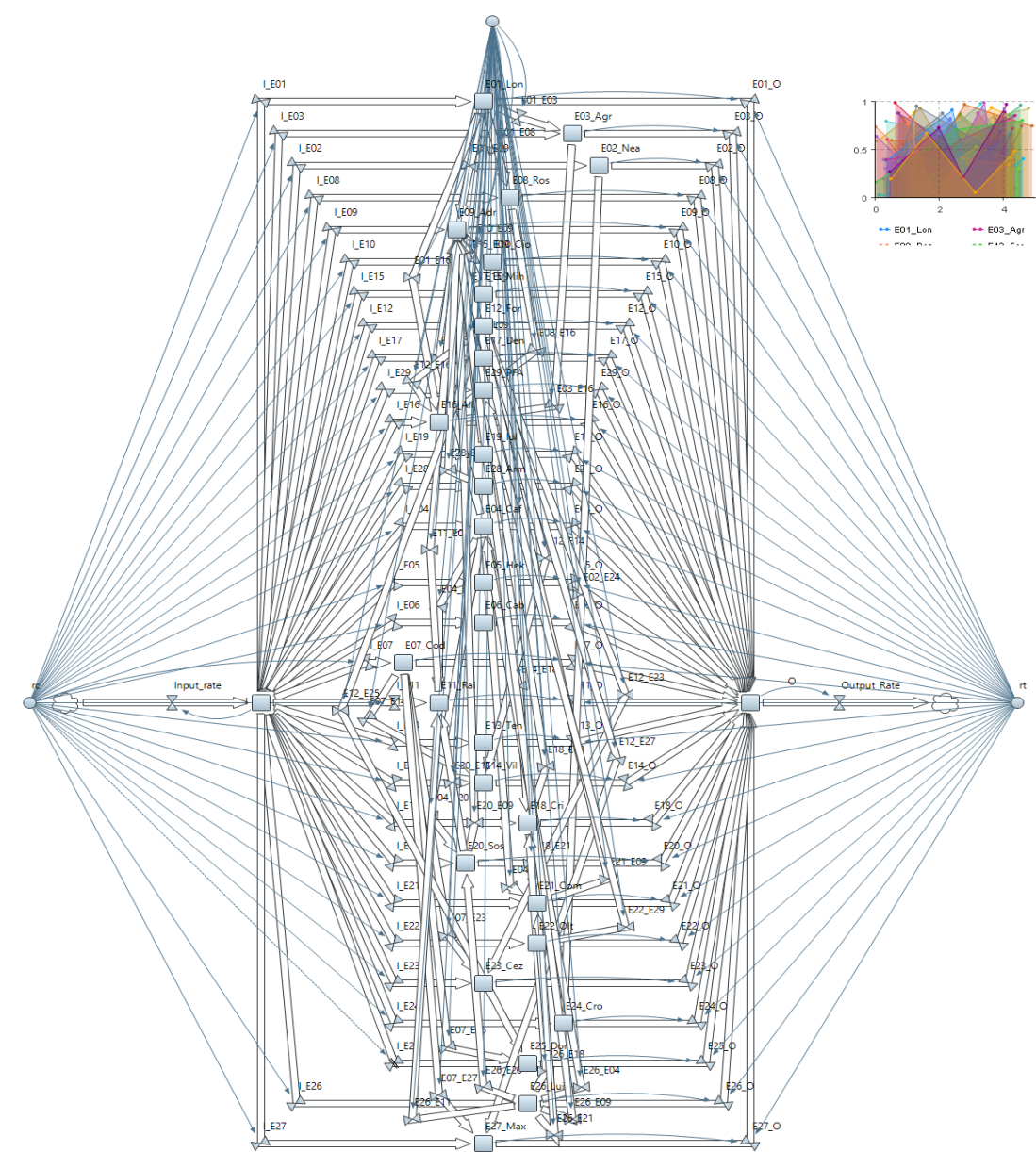

Figure 5. Model construction; the edges show the order number of the enterprises (Source: determination using AnyLogic)

The main difference between the models is the greater capacity of the SD model to simulate the reality and, thus, providing a more real picture of the entire economic environment. The great disadvantage of the SD approach is the high number of variables and thus, a longer time needed to analyze and construct the model for large economic environments, due to the nature and the amplitude of the local economy.

The SD approach entails four steps. The first and also the most important is conceptualization. The correct representation of the system in this point is crucial for the best approximation of the system behaviour.

Conceptualization has four main steps:

- The definition of the modelling purpose, which means actually setting the objective of the modelling process. Defining the purpose allows the modeler to focus on the final results and to obtain a valid usable diagram.

- The determination of the model boundary and the key variables, which consists in setting up of a context and choosing the components that form the model.

- Drawing the behaviour of the variables presented above. This step requires gathering historical data about the variables selected in the previous step or their description if data is not available.

The Enterprise column from Table 3 shows the abbreviations of the enterprises from Table 2.

- Finally, the modeler creates the mechanisms and the feedback loops, which is the final step of the conceptualization part.

The other three parts of building a model using system dynamics method are the formulation of the model, the testing and the implementation. While the formulation helps to convert diagrams to level and rate equations and testing does the validation part, the implementation applies the model to different policies and converts the results into readable data, making it usable information 
in order to make decisions on the basis of a realbased updated model of the reality.

The plot shows a trend for non-improvement of economic costs for small enterprises. This means that the most powerful enterprise is far from the others, from an economic point of view, and absorbs most of the resources and produces most of the economic input and output at a specific economic level.

The economic trend (calculated using linear regression, shown in the legend of Figure 6 for all enterprises) shows a need in the qualitative development, i.e., in the diversification of the economic activity on several economic branches, mostly related to industry, processing and commerce.

As shown in Figure 6, the statistical parameters of the economic environment evolution certify the trend by the strong relation shown by the $\mathrm{R}$ factor (close to 1).

A solution for larger environments would be their division into smaller micro-environments and their separate analysis followed by their reunification.

\section{Conclusion}

The improvements (finer results and better representation of the model) provided by this paper based on the degree thesis of one of the authors that studied this topic (Bold, 2016) are crucially for a real-based system that would be as close as possible to the real economic market of a geographic area. This model can also be used for departments within a company, as it will be shown in further papers, where enterprises are replaced by departments within an enterprise in the whole concept of the economic map (Tița et al., 2018); thus its importance is greater, because a system can be a unit in a bigger system (there can be systems made up of subsystems then such systems can also be formed from other sub-subsystems and so on).

The results demonstrate that the powerful enterprises tend to have a growth for the next five years, which underlines the need for the small enterprises to be supported. Regarding the improvement of the model, the next steps are the implementation of an application that would

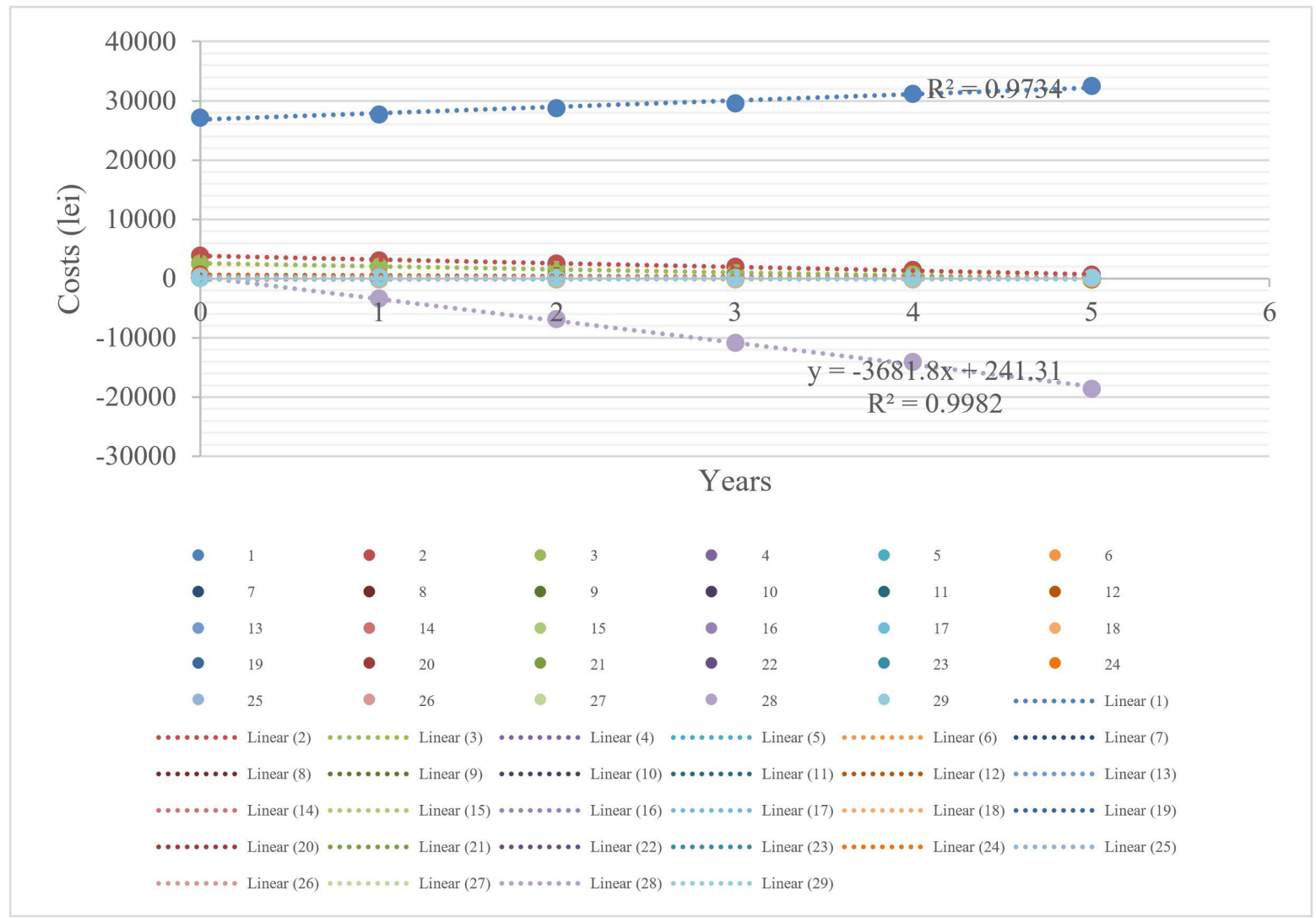

Figure 6. Evolution of the total cost of the enterprises, according to the results from Table 3 (Source: own construction) 
build a dynamic model based on existent data, on a platform that would have the advantage of being accessed easily by the usual farmers or economists.

Another future work would consist in finding solutions to others methods (developments of actual methods) and collecting more important information about the enterprises. Within this method, it could also be studied the case of networking the systems when the quantities of products/services replace the costs. Another direction of this future approach would be to describe a method to develop the usage of the system for the departments within an enterprise.

\section{REFERENCES}

Archibugi, D., Howells, J. \& Michie, J. (1999). Innovation systems in a global economy, Technology Analysis and Strategic Management, 11(4), 527-539. DOI:10.1080/095373299107311.

Banciu D., Rădoi M. \& Belloiu S. (2020) Information Security Awareness in Romanian Public Administration: An Exploratory Case Study, Studies in Informatics and Control, 29(1), 121-129. DOI: 10.24846/v29i1y202012

Bold, N. (2016). The role of the informatics systems in the knowledge and development of enterprises and the relationships between them. The development of Șerbănești village from the rural development perspective - case study. Degree thesis, 5-40.

Coyle, R. G. (1977). Management System Dynamics. John Wiley and Sons Ltd, Chichester.

Doll, C. N. H., Muller, J.-P. \& Morley, J. G. (2006). Mapping regional economic activity from night-time light satellite imagery, Ecological Economics, 57(1), 75-92.

Duque, J. C., Rey, S. J. \& Gómez, D. A. (2009). Identifying industry clusters in Colombia based on graph theory, Ensayos Sobre Politica Economica, 59(1), 13-45.

Forrester, J. W. (1994). System dynamics, systems thinking, and soft, System Dynamics Review, 10(2-3), $245-256$

Geunes, J. \& Pardalos, P. M. (Eds.) (2005). Supply Chain Optimization. Springer, US.

Grabher, G. (2006). Trading routes, bypasses, and risky intersections: mapping the travels of 'networks' between economic sociology and economic geography, Progress in Human Geography, 30(2), 163-189.

Koulouriotis, D. E., Diakoulakis, I. E. \& Emiris, D. M. (2001). A Fuzzy Cognitive Map-based Stock Market Model: Synthesis, Analysis \& Experimental Results. In The 10th IEEE International Conference on Fuzzy Systems, Vol. 1, (pp. 465-468). DOI: 10.1109/ FUZZ.2001.1007349
Nagurney, A. (2006). Supply Chain Networks Economics. Dynamics of Prices, Flows and Profit. Edward Elgar Pub, Northampton, MA, USA.

Nasirzadeh, F., Khanzadi, M. \& Mir, M. (2018). A hybrid simulation framework for modelling construction projects using agent-based modelling and system dynamics: an application to model construction workers' safety behavior, International Journal of Construction Management, 18(2), 132-143.

Necula, R. (2011). Innovation in agriculture-use of computer systems, Agricultural Management Series I, 13(1), 385-390.

Quoniam, L., Pauluci, R. \& Jorge, C. (2007). Networks of the economic intelligence in France: mapping and visualisation of knowledge. In 11th International Conference on Scientometrics and Informetrics. ISSI, Madrid, Spain.

Roberts, F. S. (1989). Applications of combinatorics and graph theory to the biological and social sciences: Seven fundamental ideas, Applications of Combinatorics and Graph Theory to the Biological and Social Sciences. 1-37. Springer-Verlag New York Inc. New York, NY, US.

Saavedra, M. R. M., de Fontes, C. H. O. \& Freires, F. G. M. (2018). Sustainable and renewable energy supply chain: A system dynamics overview, Renewable and Sustainable Energy Reviews, 82(Part 1), 247-259.

Stoian, E., Dinu, T. A. \& Stoicea P. (2011). Farm management through costs and economic performance of activities, Agricultural Management/Lucrari Stiintifice, Seria I, vol. Management Agricol, 13(2), 303-310.

Tiţa, V. \& Bold, N. (2016). Educational Aspects of Market Mapping: Student Learning of Economic Issues Regarding Markets Using a Model Based on Graphs. In Proceedings of the 11th International Conference on Virtual Learning, Bucharest University Press (pp. 329-333).

Tiţa, V., Bold, N. \& Anastasiu, D. P. (2018). Developing a model for mapping an enterprise or an 
economic environment, Procedia Manufacturing, 22, $872-877$

Wang, D., Nie, R., Long, R., Shi, R. \& Zhao Y. (2018). Scenario prediction of China's coal production capacity based on system dynamics model, Resources, Conservation and Recycling, 129, 432-442.

Yiwen, Y., Liu, G. \& Zhang, Z. (2000). Stock market trend prediction based on neural networks, multiresolution analysis and dynamical reconstruction. In Proceedings of the IEEE/IAFE/INFORMS 2000
Conference on Computational Intelligence for Financial Engineering (CIFEr)(Cat. No. 00TH8520), vol. 21 (pp. $155-156)$.

Zhikun, D., Wenyan, G., Shenghan, L \& Zezhou, W. (2018). System dynamics versus agent-based modeling: a review of complexity simulation in construction waste management, Sustainability, 10, 2484. DOI: 10.3390/su10072484. Available at: $<$ https://www.mdpi.com/2071-1050/10/7/2484>, last accessed: 25.10.2019. 